\title{
Teacher Identity Development in Professional Learning: An Overview of Theoretical Frameworks
}

\author{
${ }^{1}$ Hussain Ahmad, ${ }^{2}$ Sayyed Rashid Shah, ${ }^{3}$ Fatmawati Latada, ${ }^{4}$ Muhammad Nubli Wahab \\ ${ }^{1}$ English Language Institute, King Abdul-Aziz University, Jeddah, Saudi Arabia \\ ${ }^{2}$ Faculty of Languages \& Translation, King Khalid University, Abha, Saudi Arabia \\ ${ }^{3,4} \mathrm{C}$ entre for Modern Languages and Human Sciences, University of Malaysia Pahang (UMP), Malaysia
}

Correspondence: Hussain Ahmad, English Language Institute, King Abdul-Aziz University, Jeddah 21589, Saudi Arabia Tel: 966-591-693-221. E-mail: hahmad. me@gmail. com

\begin{abstract}
This article discusses the need and essential components of theoretical frameworks and elaborates on the most notable theories that may be employed in the process of conceptualizing teacher identity development in different professional learning experiences. First of all, it explains the significance of including a theoretical framework and identifies various factors that researchers might consider for establishing a justifiable theoretical base for their research studies. Introducing the construct of teacher identity and its various attributes, the article then goes on to present seven theories that might influence the construction of teacher identity teacher learning in an educational setting. Hence the article explicates how educational researchers should take into consideration the theoretical underpinnings of Wenger's Communities of Practice (CoP), Vygotsky's Socio-cultural Theory, Activity Theory, Positioning Theory, Cultural Production and Practice Theory, Dialogical Self-theory, and/or The Dynamic System Model of Role Identity (DSMRI) in order to show their philosophical, epistemological, methodological, and analytical approach to research studies in the realm of teacher identity. At the end, the article suggests some practical steps on implementing one or more theories and conceptualizing teacher identity in educational research.
\end{abstract}

Keywords: Teacher professional identity development, teacher identity attributes, theoretical framework

\section{Introduction}

The notion of teacher identity has recently emerged as a significant factor in teaching profession that can have a huge impact on teaching and learning outcomes. A considerable amount of research has attempted to unravel the concept of teacher identity and understand how it can be conceptualized and may influence the teaching-learning processes. It has been noticed that teacher identity appears in almost all kinds of teaching situations whether they occur inside a classroom or in the outside world. Although its vital role is widely acknowledged, researchers and scholars have paid little attention to investigate and identify factors that might contribute to teacher professional identity development. Nevertheless, teacher professional learning is considered one of the most notable sites for teacher identity development. Moreover, teacher education and professional development initiatives with a focus on content and pedagogy can potentially contribute to the multiplex process of teacher identity development.

In the realm of teacher education, identity development process in professional learning experiences hinges on a theoretical framework that is among the most important considerations for identity researchers. However, for novice researchers, identifying and applying a theoretical framework can be "the most difficult" aspect of a research endeavor (Iqbal, 2007, p.17). Acknowledging the significant role as well as the intricate nature of theoretical framework and its 
application in professional identity research, the current paper discusses its essential components and elaborates on the most notable theories that may be employed in the process of teacher identity development in educational contexts.

\section{Why Theoretical Framework}

Over the past three decades, there has been an increasing emphasis on including theoretical framework in masters or $\mathrm{PhD}$ dissertations (Malendez, 2002), since most supervisors and committee members require a dissertation to be informed by a single relevant theory or a set of related and interconnected theories. Despite this significance, oftentimes it is not easy for students to come up with a workable theoretical framework. A theoretical framework is "a structure that guides a research by relying on a formal theory... constructing by using an established, coherent explanation of a certain phenomenon and relationships" (Eisenhart, 1991, p.205). Based on this definition, theoretical framework is derived from an acceptable theory that provides philosophy, epistemology, methodology, and analytical approach to a dissertation (Grant \& Osanloo, 2014). Moreover, it offers a grounding base for supporting and structuring a study's rationale as well as an underlying thread permeating all dissertation components. In a more succinct manner, Lysaght (2011) highlights the practical aspects of a theoretical framework in a research study:

A researcher's choice of framework is not arbitrary but reflects important personal beliefs and understandings about the nature of knowledge, how it exists in relation to the observer, and the possible roles to be adopted, and tools to be employed consequently, by the researcher in his/her work. (p. 572)

Since theoretical framework reflects researcher's assumptions, ethics and personal beliefs, Grant and Osanloo (2014) state that it should be aligned with the research problem, purpose statement and significance of the study. Additionally, theoretical framework should serve as an anchor for data analysis, discussion and conclusion of a dissertation or thesis. Emphasizing the explicit identification and application of a theoretical framework, Sarter (2005) contends that a study without justifiable theoretical base is of "limited usefulness of findings and conclusions" (p.494).

Choosing the right theoretical framework for a study depends on a number of factors. Among these are researcher's own worldview and his/her conceptualization of the stated research problem (Grant \& Osanloo, 2014) as wells as the different variables in a study that are measurable and identifiable constructs. In social and behavioral sciences, researchers' own biases provide a solid background for analysis and interpretation of data; therefore, theoretical framework is a reflection of researchers' fundamental beliefs about the issue under investigation. For example, if a researcher believes in the economic interpretation of history, helshe will never choose Adam Smith's notion of the wealth of nation as a theoretical framework; rather he/she will go for Marxist view of economy. According to Grant and Oslanoo (2014), the following are the salient features of the most appropriate theoretical framework:

1. Begin by identifying your beliefs.

2. Consider several theories that intersect nicely with your epistemological values and broaden your way of thinking about the concepts in your study.

3. Develop a working knowledge of the theories and understand why each theory is important to you.

4. Conduct a brief literature review to find support for your theories.

5. Consult the ProQuest Dissertations and Theses Database to review how others have applied the specific theories you are considering.

6. Consider arguments that oppose your beliefs and theories.

7. Apply answers to "how" the theory connects to your problem, the study's purpose, significance, and design. 
8. Select one theoretical framework that provides a solid, descriptive 'blueprint' for your reader. (p.19)

In addition to the above mentioned features, the choice of theoretical framework depends on the different research elements which together form a harmonious whole in the form of a research project, since according to Cohen, Manion and Morrison (2018) "a theory is a statement, suggestion or proposition that brings together concepts and constructs into a coherent whole, framework or system which has clearly set limits and assumptions" (p.165). In quantitative or mixed-method studies these attributes or constructs are called variables (dependent and independent). Therefore, the best suited theoretical framework has all the recognizable aspects of a dissertation. In the case of teacher professional identity, these recognizable aspects are identity attributes or constructs.

\section{Teacher Identity Attributes}

According to the socio-cultural standpoint (Wenger, 1998), a teacher always strives to become a certain sort of person who is compatible with his dreams, aspirations and future self. That is, they are in search of an identity that may help them achieve what they want. Teacher identity has been defined in various ways. Some believe it as 'a certain "kind of person" in a given context' (Gee, 2001, p. 99); while others define it 'the intersection of personal, pedagogical, and political participation and reflection within a larger sociopolitical context' (Hoffman-Kipp, p. 153). After studying a plethora of teacher identity definition, it seems that not two identity scholars agree on a single definition of teacher identity; however, "there is a general acknowledgement of its significance" (Izadinia, 2013, p.695). For example, it plays a vital role in shaping and reshaping teachers' teaching philosophy, their decisions about the teaching content and process, their relationship with students, with other teachers as well as the society (Beijaard, Meijer, \& Verloop, 2004). As teacher identity is fluid, continuous, changeable and not stable and pre-determined (Beijaard et al., 2004; Beauchamp \& Thomas, 2009), there are no fixed and established constructs that are constituent factors of teacher identity. Nevertheless, researchers have highlighted certain attributes, and all or a combination of these attributes form teacher identity in a given context. For instance, according to Beauchamp and Thomas (2009), teacher identity is influenced and formed by emotions, reflections, discourse, agency and context. Izadinia (2013) identified the following sociocognitive factors that are the basis of teacher professional identity: reflection, relationship with students, colleagues, as well as parents, sense of agency, self-awareness, critical conciseness, teacher voice, confidence, and cognitive knowledge. Similarly, Pennington and Richards (2016) view teacher identity in the form of a set of competencies, which are: teachers' language, disciplinary knowledge, teaching context, self-awareness, student learning, knowledge into practice as well as practice into knowledge, and membership in learning communities. Likewise, Ahmad, Latada, Wahab and Shah (2018) identified the following five attributes that constitute teacher professional identity in relation to teacher learning to teach: context, collaboration, classroom practices, teacher self-efficacy and agency. Finally, Kaplan, Garner and Semo's (2015) teacher identity model has four distinctive yet interconnected components: "(1) ontological and epistemological beliefs; (2) purpose and goals; (3) self-perceptions and self-definitions; and (4) perceived action possibilities" (p.6). Furthermore, in their identity model teacher agency is playing a vital role.

Keeping in view researcher' world-view, research problem and teacher identity attributes such as mentioned above, identity studies should have a befitting theoretical framework to justify implementing it. 


\section{Theories of Teacher Identity Development}

A theory to be included in a theoretical framework should have certain characteristics. The foremost one is that the constructs a theory presents should be testable and measurable which stands empirical scrutiny (Cohen, 2018). That is a theory that has empty rationalizations may not serve as a theoretical framework. Secondly, the constructs should be logically interconnected to present a complete picture of a social behavior and social change (Merton, 1967). Teacher identity theories presented in this paper fulfill the criteria of being testable and encompassing interconnected propositions. Besides, these theories have been frequently used to conceptualize teacher identity development in professional learning experiences.

\section{- Wenger's Communities of Practice (CoP)}

In dissertations, Wenger's (1998) communities of practice (CoP) is the most oft-used theory in studying teacher professional identity development in professional learning as teacher learning is mostly framed within socio-cultural paradigm. A community of practice is constituted by a group of people with a specific aim who work together to improve their specific practice (Lave \& Wenger, 1991; Wenger, 1998; Wenger, 2010). Since socio-cultural learning in CoP is situated learning which results in social, cognitive and emotional development, Wenger (1998) states that social "learning transforms who we are and what we can do" and thus, "it is an experience of identity" (p. 125). Therefore, teacher professional development is a social learning site where teacher professional identity evolves (Wenger, 2010). There are three pillars of CoP: the domain, the community, and the practice. In the case of teachers, domain is teaching a particular subject, such as EFL; community is a group of teachers who come together to develop their teaching skills and expertise; and practice is a shared repertoire of resources and tools that teachers develop as a result of social interaction. In recent years many dissertations around the world that have investigated teacher identity development in teacher learning have utilized $\mathrm{CoP}$ as a theoretical underpinning; for instance, Fajardo-Castaneda (2014), Rwanda; Chan (2014), Hong Kong; Hamiluglu (2013), Turkey; Hendrickson (2016), US; Riyanti (2017), Indonesia; Rutaisire (2012), Rwanda; and Subryan (2016), Canada.

However, care is needed in implementing CoP in different contexts, as CoP may not be a useful theoretical framework where teacher learning does not stem from social and collegial interactions. For example, CoP gives prime importance to the creation of a shared repertoire of practices and experiences through negotiation; however, this unstructured engagement can hardly yield any results in an educational setup where classroom practices are institutionally sanctioned (Lee \& Shari, 2012). For instance, in the context of the current study, teachers engage in communities for the purpose of sharing their practices; however, these discussions have an approved agenda led by a group leader who is normally appointed by the institution. Therefore, implementing communities of practice in the contexts such as ours where the administrative watch on the practices is tight is "building an airplane in the air" (Bruce, 2009). The same idea is echoed by Xu (2017) by claiming that traditional social theories such as Wenger's communities of practice were not designed to study language teacher identity in all situations and therefore a collaborative research framework is needed that could be generalized to different teaching contexts.

\section{- Vygotsky's Socio-Cultural Theory}

Vygotsky's social constructivism is another theory that provides theoretical edifice to teacher identity development. Indeed, it is regarded that Vygotsky's socio-culturalism is a source of all socio-cultural and socio-cognitive theoretical propositions. According to Vygotsky (1978), "learning is a necessary and universal aspect of the process of developing culturally organized, specifically 
human psychological function" (p. 90). In his view, cognitive development sprouts during social encounters within the zone of proximal development (ZPD), as leaning occurs from interacting with more knowledgeable peers. ZPD is "the distance between the actual developmental level as determined by independent problem solving and the level of potential development as determined through problem-solving under adult guidance, or in collaboration with more capable peers" (Vygotsky, 1978, p.86). In the case of teachers, Vygotsky's theory would situate teacher professional learning as a cultural activity located within a social landscape wherein teachers learn from each other as well as from trainers or mentors.

Since Vygotsky's theory could be categorized as a grand theory (Cohen et al., 2018) which provides a large-scale non-empirical framework, it is rarely used in isolation in the domain of teacher identity development. That is, it offers an over-arching concept of teacher development in sociocultural arena in conjunction with other theories that define specific testable teacher identity constructs.

\section{- Activity Theory}

Pioneered by Vygotsky, an extension of social constructivism, activity theory was developed and promoted by Russian and Western scholars, such as Luria, Leont'ev, Engeström, and Wertsch. An activity theory is "grounded in an assumption about appropriate roles, goals, and means used by the participants in that setting" (Wertsch, 1985, p. 212). According to Sannino, Daniels, and Guierrez (2009), the main tenet of activity theory is that all social activities are object-oriented and are goal driven. Therefore, "change in the goal of a task inevitably leads to a significant change in the structure of the psychological process which carry it out" (Luria, 1979, p. 172), and an "activity does not exist without a motive" (Leont'ev, 1978, p. 62). A goal, therefore, is the main drive behind meaningful human activities.

Activity theory has undergone changes and has reached us in three stages. The first stage was based on Vygotsky's notion of mediation which views human actions from individual perspectives (Engeström, 2001). The second stage views human activities from collective standpoint (Engeström, 2001; Leont'ev, 1978). The third stage is characterized by the creation of conceptual tools to "understand dialogue, multiple perspectives and networks of interacting activity systems" (Engeström, 2001, p. 135). Identity researchers (e.g. Riyanti, 2017) situate teacher identity development in the third stage of the activity theory which considers teacher learning as a set of interrelated activities for achieving common teaching goals. According to Engeström (2001), activity theory comprises of six interconnected constructs: subject, object, community, tools, rules, and division of labor. In teacher professional learning, subject is a group of teachers whose viewpoints lead the activity; object is the motive to develop teaching practices as well as professional identity; tools are teaching approaches, methods and methodologies; rules are referred to norms and conventions that regulate activity; community represents all stakeholders in teaching and learning process, such as teachers and students; and division of labor is the manner in which tasks are divided among teachers according to hierarchical structure.

\section{- Positioning Theory}

Like activity theory, positioning theory has descended from social constructionism and is widely used as a theoretical framework in teacher identity development studies. Positioning theory states that social realities are generated in and through conversation and during the process of conversation positioning is "one way to uncover how individuals construct and enact identities during moment-tomoment interactions" (Vetter et al., 2013, p.233). According to this theory, identities are socially constructed through discourse. In the context of teacher identity development, we do not consider 
discourse only as language in use (Fairclough, 2003), but discourse as "ways of behaving, interacting, valuing, thinking, believing, speaking, and often reading and writing, that are accepted as instantiations of particular identities" (Gee, 2012, p. 3). Since during discourse individuals generate their own storylines based on their positions they hold, "positions are relational, in that for one to be positioned as powerful others must be positioned as powerless" (Harré \& van Langenhove, 1999, pp.2). Consequently, the power factor provides the negotiation of identities during professional development experiences. Moreover, teacher identity negotiation occurs when professional development is imposed and is delivered in a top-down manner wherein teachers have no or little say in choosing the PD content; therefore, positioning theory is applicable in situations where PD is prescribed by PD developers or institutions.

\section{- Cultural Production and Practice Theory}

According to cultural production and practice theory (Giddens, 1979; 1984), identity formation is culturally produced in spaces, such as teacher professional learning, where identities are played out. According to Levinson and Holland (1996), "through the production of cultural forms, created within structural constraints of sites such as schools, subjectivities form and agency develops" (p. 14). This perspective of identity formation stands in contrast to the previous notions which view identity formation a cultural reproduction activity and thereby considers human actions to be deterministically reproduced. According to the new understanding, the sites for identity formation and development are not dominant discourses, but local contexts where individuals influence the context and vice versa. According to Varghese (2010), cultural production has the same meaning as situated learning suggested by Lave and Wenger (1991) in the context of identity formation which proposes that learning and identity formation occur when people participate in communities of practice. Since learning in communities of practice emphasizes the situatedness of learning and identity formation, Lave (1997) believes that the "processes of learning and understanding are socially and culturally constituted...what is to be learned is integrally implicated in the forms in which it is appropriated" (p. 18). Although Lave and Wenger's communities and cultural production highlight the importance of sociopolitical context in learning and identity making process, communities of practice tend to favor reproduction of meaning and avoids opposing the mainstream notion of learning and understanding. Nevertheless, both theories in tandem can provide a strong theoretical framework for teacher identity development in professional learning, either teacher education or professional development, in contexts where teacher learning is viewed as a mix of cultural production and conformity to established notions. Although cultural production derides the mainstream notion of identity making, in some teaching contexts where conformity to institutional rules is deemed necessary the local meaning of identity is not less stagnant and stereotypical than the mainstream meaning.

\section{- Dialogical Self-Theory}

Dialogical self-theory (DST) by Dutch psychologist Hubert Hermans bridges the concept of self and dialogue for a better conceptualization of the relation between self and society. According to Meijers and Hermans (2018), DST "weaves two notions, self and dialogue, together in order to create a bridge between the individual and the society" (p.7). In traditional terms self refers to the internal process happening in one's mind, while dialogue being an external process occurs between people. In addition to self and society, self has many I-positions which harbor different and sometimes conflicting views about a social phenomenon. Meijers and Hermans (2018) have called the different I-positions "a society of mind" (p.7). In this way, the dialogical self-theory shuns the self-society dualism and instead advocates a self-less society which encapsulates self and society on 
the one hand and minimizes the clash among different I-positions on the other. From the Vygotskian standpoint, such dialogues whether among I-positions or between the self and the society settle down in the reformulation of a person's identity.

DST provides a theoretical framework for teacher identity development by regulating the diverse aspects: "that is, I as a person and I as a professional" (Meijers \& Hermans, p.98). According to Wenger (1998), social learning in the form of professional learning provides teachers a site to reformulate their professional identities. Therefore, in professional learning there are many possibilities for teachers to broaden their pedagogical horizons, as these learning experiences offer a wide range of perspectives to be shared among other teachers. Inducting teachers into dialogic talk during professional learning provides them a space wherein they share different perspectives and negotiate their identities. Thus, this theoretical framework can be useful in studying teacher professional identity development in relation to professional learning where there are teachers from diverse socio-cultural and educational backgrounds. In addition, such professional learning sites give teachers space to engage in dialogue and think together, position their different perspectives, and allow themselves to cross their own boundaries to accommodate other's positions. We argue that DST in combination with Vygotsky's (1978) socio-cultural theory or Wenger's (1998) communities of practice provides a workable theoretical framework to teacher learning and as a result their identity reformulation.

\section{- The Dynamic System Model of Role Identity (DSMRI)}

According to Kaplan et al., (2015), the Dynamic Systems Model of Role Identity (DSMRI) is understanding teacher role identity and its development within socio-cultural contexts. Teacher professional role identity (RI) is the presentation of self-image as a teacher and how he/she feels comfortable in the position of a teacher (Beijaard, Meijer, \& Verloop, 2004). RI as an anchor for teachers to guide them through their decision making with regards to teaching related matters. In traditional sense, teacher identity theories view identity formation and development in two broad ways: constructs model and holistic socio-cultural model. According to constructs model, teacher identity is formed by self-related constructs, such as context, collaboration, self-efficacy, and involves quantitative methods to measure the change in these constructs (Roth, 2014) to yield empirical findings. Whereas, socio-cultural model explores the holistic subjective meanings of teacher identity in a specific socio-cultural context (Beauchamp \& Thomas, 2009) and involves qualitative methodologies to study teaching and teacher identity in a particular social setup to yield an in-depth description of teacher change. Both approaches have strengths as well as limitations with regard to teachers' lived experiences. Thus, DSMRI is a model of "teacher professional RI that integrates the strengths and compensates for the limitations of these two approaches" (Kaplan, et al., 2015, p.5).

DSMRI has four independent components: ontological and epistemological beliefs; purpose and goals; self-perceptions and self-definitions; and perceived action possibilities. The four constructs are contextually constructed and related to the teaching profession in general and to a specific teaching or learning phenomena in particular. In contrast to other several theoretical frameworks of teacher change which represent one or two components, DSMRI incorporates all four components in a single model. Additionally, the four components are context-dependent. In a more succinct way, teacher identity change is interconnected to contextual factors owing to which teaching and teacher change are highly contextualized. Hence, DSMRI as a meta-theoretical approach provides a framework of teacher RI change in professional development. When we conceptualize change, it could be in one, two or all four salient features of the teacher RI. Therefore, understanding of RI and how its components undergo change as a result of teacher learning experiences is of utmost importance to PD developers and teacher trainers. 


\section{Conclusion}

Taken together, after conceptualizing teacher identity development in teacher learning the following conclusions are drawn. Firstly, the above and several other theories that provide theoretical underpinnings to teacher identity development specifically in learning experiences have stemmed from or influenced by socio-constructionist and socio-cultural traditions. It shows that identity being non-linear, fluid and at times chaotic has a reciprocal relationship with societal and contextual factors. More exactly, teacher identity manifests the socio-cultural context which affects teacher beliefs, perceptions and teaching practices, and teacher identity influences society in an in-direct manner through his/her classroom performance. Therefore, theories that consider human development as a socio-cultural process, as opposed to cognitive theories, are the most appropriate to be employed as theoretical framework in teacher identity studies.

Secondly, employing a theoretical framework in the arena of teacher identity is dependent on researcher's beliefs and world view about teacher development in general and teacher identity development in particular. For instance, a researcher who believes in teacher-centeredness and may hold the epistemic belief that learners construct knowledge through interaction will go for a theory that may conform to this view. Whereas, a researcher who sees student-learning as transmission of knowledge may opt for a more teacher-centered theoretical configuration. Furthermore, the context of teacher identity development is a crucial factor in selecting a theoretical framework; a researcher will choose a theoretical framework that reflect the nature of teacher learning, general belief about teacher's role, and institutional goals. For example, in the context of teacher identity development in professional development, the PD content and process should be either in a top-down manner which denies teachers' involvement or in a bottom-up manner which gives teachers freedom to opt for the PD of their liking or a in a customized manner which is a mix of the first two. Accordingly, identity researchers should select a theory that is aligned with his epistemic beliefs and fulfills the contextual requirements.

Thirdly, since teacher identity development is not a simple linear and unidirectional process, oftentimes a single theory is not enough to conceptualize the complexity, multifacetedness and multiplicity of teacher identity. For instance, if teacher learning occurs through social interaction, Wenger's (1998) CoP may suffice to illustrate teacher identity, but if there are new comers then the participation crosses the boundaries of simple social interaction which would entail the inclusion of Lave and Wenger's (1991) peripheral participation. Similarly, if teacher learning is not only from each other but also from teacher trainers or more knowledgeable others, Wenger's (1998) CoP is not enough to provide an adequate theoretical base, and as a result Vygotsky's (1978) socio-cultural theory's ZPD will be involved. Thus, except in simplistic orientations, teacher identity development is not fully captured by a single theoretical framework.

Fourthly, different research methodologies require the utilization of theoretical framework accordingly. In the most subtle form, the choice of a theoretical framework depends on researcher's objectives and how these objectives are achieved, whether through quantitative, qualitative or mixed methods. Quantitative researchers will use a theory that has distinct self-related measurable constructs and the analysis yields replicable and generalizable results. While qualitative researchers will utilize a theory that deals with holistic theorization of a social phenomena which focuses on the contextualized manner of a social reality. However, in the case of mixed-methods research, a researcher can either apply a theory that fulfills the demands of both quantitative and qualitative strands or choose a multiple theoretical framework which cater to both forms of enquiries.

Finally, what happens to a theory or theories in a research study? In general, at the end of a research study a theoretical framework is viewed in three distinct ways. First, the findings conform to the philosophical bases of a theoretical framework, and thus adds to the universality of that particular theory. Secondly, the findings, in part or as a whole, contradict what an applied theory postulates, 
and question its applicability in the context of a given study. Next, the findings add to the theoretical precepts of a theory signifying the usefulness of a theory or theories in a specific context, but if applied in a similar situation more factors are added. It enhances the universality of a theoretical framework.

\section{References:}

[1] Ahmad. H., Latada. F., Wahab. M. N., Shah. S. R., \& Khan. K., Shaping Professional Identity Through Professional Development: A Retrospective Study of TESOL Professionals, International Journal of English Linguistics,8(6)(2018), 37, https://doi.org/10.5539/ijel.v8n6p37

[2] Beauchamp. C., \& Thomas. L., Understanding teacher identity: an overview of issues in the literature and implications for teacher education, Cambridge Journal of Education, 39(2)(2009), 175-189, https://doi.org/10.1080/03057640902902252

[3] Beijaard. D., Meijer. P. C., \& Verloop. N., Reconsidering research on teachers' professional identity, Teaching and Teacher Education, 20(2)(2004), 107-128, https://doi.org/10.1016/j.tate.2003.07.001

[4] Bruce. B. C., Building an airplane in the air: The life of the inquiry group. In J. $\quad$ K. Falk, \& B. Drayton (Eds.), Creating and sus-taining online professional learning communities (pp. 47-67). New York: Teachers College Press, (2009)

[5] Chan. W.N.G., The Professional Identity Development of Preservice Postgraduate Diploma in Education (English) Teachers in Hong Kong. (Doctoral dissertation) The Chinese University of Hong Kong, (2014)

[6] Cohen. L., Manion. L., \& Morrison. K., Research methods in education (5 ed) New York. Routledge, (2018)

[7] Eisenhart, M., Conceptual frameworks for research circa 1991: Ideas from a cultural anthropologist; implications for mathematics education researchers. Paper presented at the Proceedings of the Thirteenth Annual Meeting North American Paper of the International Group for the Psychology of Mathematics Education, Blacksburg, Virginia, USA, (1991)

[8] Engeström. Y., Expansive Learning at Work: toward an activity theoretical reconceptualization, Journal of Education and Work, 14(1)(2001), 133-156, https://doi.org/10.1080/13639080123238

[9] Fairclough. N., Analysing discourse: textual analysis for social research, London, New York: Routledge, (2003)

[10] Fajardo Castañeda. J. A., Learning to teach and professional identity: images of personal and professional recognition, Profile Issues in Teachers Professional Development, 16(2)(2014), 49-65, https://doi.org/10.15446/profile.v16n2.38075

[11] Gee. J.P., Identity as an Analytic Lens for Research in Education, in: Secada, W.G. (ed), Review of research in education, 25(2000), 99-125, https://doi.org/10.2307/1167322

[12] Gee. J. P., Social linguistics and literacies: ideology in discourses (4th ed). Abingdon, Oxon; New York: Routledge, (2012)

[13] Giddens. A., Central problems in social theory: Action, structure and contradiction in social action. Berkeley: University of California Press, (1979)

[14] Giddens. A., The constitution of society: Outline of a theory of structuration, Cambridge: Polity Press, (1984) 
[15] Grant. C., \& Osanloo. A., Understanding, Selecting, And Integrating A Theoretical Framework In Dissertation Research: Creating The Blueprint For Your "House", Administrative Issues Journal Education Practice and Research, (2014), https://doi.org/10.5929/2014.4.2.9

[16] Hamiloğlu. K., Turkish student teachers' reflections on their professional identity construction and reconstruction process during the practicum (Doctoral dissertation) University of Leicester, UK, (2013)

[17] Harre. R., \& van Langenhove. L., The dynamics of social episodes. In R. Harre \& L. van Langenhove (Eds.), Positioning theory: Moral contexts of intentional action, (1999), pp. 1-13, Malden, MA: Blackwell Publishing Ltd.

[18] Hendrickson. K. A., Math Teachers' Circles: The effects of a professional development community on mathematics teachers' identities (Unpublished doctoral dissertation). Ohio University, Athens, $\mathrm{OH}$, (2016)

[19] Hoffman-Kipp. P., Actualizing democracy: the praxis of teacher identity construction, Teacher Education Quarterly, 35(3)(2008), 151-164.

[20] Iqbal. J., Learning from a doctoral research project: Structure and content of a research proposal, The Electronic Journal of Business Research Methods, 5(1)(2007),11-20.

[21] Izadinia. M., A review of research on student teachers' professional identity, British Educational Research Journal,39(4)(2013), 694-713, https://doi.org/10.1080/01411926.2012.679614

[22] Kaplan. A., Garner. J., \& Semo. S., Teacher role-identity and motivation as a dynamic system, Paper presented at American Educational Research Association Chicago, IL, (2015)

[23] Lave. J. \& Wenger. E., Situated Learning. Cambridge: Cambridge University Press, (1991)

[24] Levinson. B. A., \& Holland. D. C., The cultural production of the educated person: An introduction. In B. A. Levinson, D. C. Holland \& D. E. Foley (Eds.), The cultural production of the educated person: Critical ethnographies of schooling and local practice (pp. 1-56). Albany: State University of New York Press, (1996)

[25] Lee. D. H., \& Shaari. I., Professional identity or best practices? An exploration of the synergies between professional learning communities and communities of practices, Creative Education, 3(4)(2012), 457-460, https://doi.org/10.4236/ce.2012.34070

[26] Leont'ev. Aleksei Nikolaevich., Activity, consciousness, and personality. (M. J. Hall, Trans.). New Jersey: Prentice-Hall, Inc, (1978)

[27] Lysaght. Z., Epistemological and paradigmatic ecumenism in "Pasteur's Quadrant:" Tales from doctoral research. Official Conference Proceedings of the Third Asian Conference on Education in Osaka, Japan, (2011)

[28] Meijers. F. \& Hermans. H., The dialogical self -theory in education: A multicultural perspective. Cham: Springer International Publishing, (2018)

[29] Melendez. J., Doctoral scholarship examined: dissertation research in the field of higher education studies. (Unpublished PhD dissertation). Seton Hall University, (2002)

[30] Merton. R. K., On Theoretical Sociology: Five Essays Old and New. New York: The Free Press, (1967) 
[31] Pennington .M.C. \& Richards. J.C., Teacher Identity in Language Teaching: Integrating Personal, Contextual, and Professional Factors. RELC Journal, 47(1)(2016), 5- 23, https://doi.org/10.1177/0033688216631219

[32] Riyanti. D., Teacher identity development: A collective case study of English as a foreign language preservice teacher learning to teach in Indonesian university teacher education program. (doctoral dissertation). University of Nebraska, (2017)

[33] Roth. G., Antecedents and outcomes of teachers' autonomous motivation: A self-determination theory perspective. In P. W. Richardson, S. Karabenick \& H. M. G. Watt (Eds.), Teacher motivation: Theory and practice, (2014), pp. 36-51, NY: Routledge.

[34] Rutaisire. J., An investigation into teachers' experiences of in-service training and professional development in Rwanda. (Doctoral dissertation). University of Sussex, (2012)

[35] Sannino. A., Daniels. H., \& Guierrez. K. D., Activity Theory between historical engagement and futuremaking practice. In A. Sannino, H. Daniels, \& K. D. Guierrez (Eds.), Learning and expanding with Activity Theory, (2009), pp. 1-15, New York: Cambridge University Press.

[36] Sarter. M., The consequences of atheoretical, task-driven experimentation: Theoretical comment on Paban, Chambon, Jaffard, and Alescio-Lautier (2005), Behavioral Neuroscience,120(2) (2006), 493-495, https://doi.org/10.1037/0735-7044.120.2.493

[37] Subryan. S., Exploring Secondary School Science Teacher Professional Identity: Can it be influenced and reshaped by experiences of professional development programmes? (doctoral dissertation), University of Derby, (2016)

[38] Varghese. M., Professional development as a site for the conceptualization and negotiation of bilingual teacher identities. Research and Practice in Language Teacher Education, (2010), 193-212.

[39] Vetter. A., Meacham. M., \& Schieble. M., Leveling the field: Negotiating positions of power as a preservice teacher. Action in Teacher Education, 35(4)(2013), 230-251, https://doi.org/10.1080/01626620.2013.827598

[40] Vygotsky. L. S., Mind in society: The development of higher mental process: Cambridge, MA: Harvard University Press, (1978)

[41] Wenger. E., Communities of Practice. Cambridge: Cambridge University Press, (1998)

[42] Wenger. E., Communities of Practice and Social Learning Systems: The Career of a Concept, Social Learning Systems and Communities of Practice, (2010),179-198, https://doi.org/10.1007/978-1-84996-133$2 \_11$

[43] Wertsch. J. V., Vygotsky and the social formation of mind. Cambridge, Mass: Harvard University Press, (1985)

[44] Xu. H., From the imagined to the practiced: A case study on novice EFL teachers' professional identity change in China, Teaching and Teacher Education, 31(2013), 79-86, https://doi.org/10.1016/j.tate.2013.01.006 